\title{
Efficacy and Safety of Monopolar Transurethral Resection of the Prostate on Bleeding Control in the Treatment of Benign Prostatic Obstruction: Is It Still a Good Option in Developing Countries?
}

\author{
(D) Serkan Akan, (D) Caner Ediz, (D) Eymen Özer, (D) Mehmet Pehlivanoğlu, (D) Hasan Hüseyin Tavukçu, (D) Kazım Kıymaz, \\ (D) Ömer Yılmaz \\ University of Health Sciences Turkey, Sultan Abdülhamid Han Training and Research Hospital, Clinic of Urology, Istanbul, Turkey
}

\begin{abstract}
Objective: The objective of this study is to investigate the bleeding control safety along with the need for preoperative blood preparation and postoperative blood transfusion in the transurethral resection of the prostate with monopolar system (M-TURP) for the treatment of benign prostatic obstruction (BPO).

Materials and Methods: We retrospectively analysed 379 patients with BPO who underwent M-TURP procedure between January 2016 and December 2019 at a single centre. Importantly, we collected the demographic data, use of 5-alpha-reductase inhibitor (5-ARI), postoperative haemoglobin (Hb) and haematocrit levels, platelet counts, and transfusion rates of these patients.

Results: The minimum, maximum and the mean ages of the patients were 43,79 and $67.44 \pm 7.74$ years, respectively. The minimum, maximum and the mean prostate volumes of the patients measured via transrectal ultrasonography were 30,95 and $53.42 \pm 18.12 \mathrm{~mL}$, respectively. In total, 99 patients (26.1\%) had received 5-ARI for at least three months before surgery. The mean decrease of the preoperative $\mathrm{Hb}$ in the postoperative $48^{\text {th }}$ hour was $0.99 \pm 0.87 \mathrm{gr} / \mathrm{dL}$. Only 9 patients $(2.4 \%)$ received the transfusion of blood products (erythrocytes or fresh frozen plasma). The preoperative Hb level was inversely and significantly correlated with the decrease in postoperative $\mathrm{Hb}$ and the need for transfusion $(\mathrm{p}<0.05)$. The preoperative use of 5 -ARI was not associated with postoperative decrease in $\mathrm{Hb}$ and the need for transfusion. The preoperative cut-off value of $\mathrm{Hb}$ for predicting a substantial decrease in $\mathrm{Hb}$ and transfusion need after M-TURP was calculated as 12.45 $\mathrm{gr} / \mathrm{dL}$ with a sensitivity and specificity of $77.8 \%$ and $86.8 \%$, respectively.

Conclusion: M-TURP is still a safe and effective option in BPO treatment in developing countries. Importantly, we do not recommend the routine preoperative blood preparation in index patients with $\mathrm{Hb}$ level higher than $12.45 \mathrm{gr} / \mathrm{dL}$.

Keywords: Benign prostatic obstruction, bleeding control, haemoglobin, monopolar transurethral resection, transfusion
\end{abstract}

\section{Introduction}

Transurethral resection of the prostate (TURP) is the gold standard in the treatment of lower urinary tract symptoms caused by benign prostatic obstruction (BPO) (1). With the observation of its long-term efficacy in randomised controlled trials, TURP has maintained its success in the surgical treatment of BPO (2).

Bleeding is one of the most severe complications of TURP. Its persistence may necessitate blood transfusion and can lead to clot retention in the postoperative period (3). Although
TURP is one of the most common and currently performed urological procedures, there are some doubts as to whether the routine tests for blood group or antibody screening should be conducted on these patients. The major international urological associations do not have specific recommendations regarding the routine tests for blood group or antibody screening before TURP and post-TURP haemoglobin $(\mathrm{Hb})$ control; however, these tests are performed routinely in many hospitals (4).

Despite the technological improvements in the endoscopic surgery of BPO, TURP with monopolar system (M-TURP) is

Cite this article as: Akan S, Ediz C, Özer E, Pehlivanoğlu M, Tavukçu HH, Kıymaz K, Yılmaz Ö. Efficacy and Safety of Monopolar Transurethral Resection of the Prostate on Bleeding Control in the Treatment of Benign Prostatic Obstruction: Is It Still a Good Option in Developing Countries? Bull Urooncol 2020;19(3):157-161

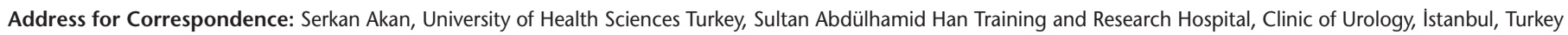
Phone :+90 2165423232 E-mail: drserkanakan@hotmail.com ORCID-ID: orcid.org/0000-0002-6066-0401 Received: 17.02.2020 Accepted: 31.03.2020 
commonly performed in developing countries because of the economic reasons. The purpose of this study is to assess the effects of M-TURP on bleeding control, the need for blood transfusion after M-TURP and the problems of preoperative blood preparation.

\section{Materials and Methods}

\section{Study Design}

Due to the fact that this study is a retrospective, ethical committee approval was not obtained. We retrospectively collected the records of the patients with the diagnosis of BPO (after other failed medical treatment) who underwent M-TURP between January 2016 and December 2019.

Inclusion and Exclusion Criteria

This study included patients with BPO who were resistant to medical treatment, aged between 40 and 79 years, and underwent M-TURP. The exclusion criteria of this study were: age equal or greater than 80 years, presence of haematuria, antithrombotic/anticoagulant use, heart failure, patients with platelet (PIt) count and/or function anomaly, additional urinary tract disease such as bladder tumour or bladder stone, and inadequate data. Few patients who had a prostate gland volume (PV) equal or greater than $100 \mathrm{~mL}$ and who underwent the M-TURP procedure were not included because within the study period nearly all of the patients who had a PV equal or greater than $100 \mathrm{~mL}$ underwent open prostatectomy.

We collected the information regarding the age of the patients, use of $5 \alpha$-reductase inhibitor (5-ARI) and other medications, demographics, PV measured by transrectal ultrasonography, complete blood count preoperatively and in the postoperative $48^{\text {th }}$ hour, and transfusions. In four patients, who were rehospitalised because of late bleeding after discharge, the complete blood count in the $48^{\text {th }}$ hour of the second admission was used in the calculations.

The patients were grouped according to their age, older or younger than 65 years, and whether blood transfusion was performed or not. We compared the study parameters among these groups. Additionally, we assessed the correlation between $\mathrm{Hb}$ changes from the preoperative period to the postoperative $48^{\text {th }}$ hour and the other study parameters.

\section{Blood Transfusion}

We adopted a restrictive transfusion strategy (5). No transfusion was performed in the patients with a $\mathrm{Hb}$ level greater than 10 $\mathrm{g} / \mathrm{dL}$, whereas all the individuals with a $\mathrm{Hb}$ level lower than 7 $\mathrm{g} / \mathrm{dL}$ received erythrocyte suspension (ES) transfusion. Between these threshold $\mathrm{Hb}$ levels, the decision of transfusion was made according to the concurrent organ ischaemia, predicted consequences of the bleeding, intravascular volume status of the patient and the risks arising out of inadequate oxygenation. Fresh frozen plasma (FFP) was administered in the patients who received high amounts of ES to prevent dilutional coagulopathy. Other blood products were not used in the study.

\section{Surgical Technique}

All the surgical procedures were performed in a routine manner by specialist urologists with an experience of performing more than 100 TURP operations. M-TURP was conducted in a standard manner by using the $26 \mathrm{Fr}$ continuous flow resectoscope (Karl Storz GmbH \& Co. KG, Tuttlingen, Germany) or 24 Fr single-flow resectoscope (Karl Storz GmbH \& Co. KG, Tuttlingen, Germany) with a monopolar loop electrode. The electrocautery system (Valleylab Force FXTM, Boulder, CO, USA) was used with the power settings of 120 and 80 Watts for cutting and coagulation, respectively. About $0.5 \%$ mannitol solution [Rezosel® (OSEL, Istanbul, Turkey)] was used as irrigation fluid during surgery. Postoperatively, a $22 \mathrm{Fr}$ three-way latex Foley catheter was placed in all the patients, and the catheters were removed 48$72 \mathrm{~h}$ after the operation.

\section{Statistical Analysis}

We conducted statistical analyses by using IBM SPSS Statistics 22 (IBM SPSS, Turkey) computer program. We controlled the normal distribution of the data by Shapiro-Wilks test. Besides the descriptive statistical methods (mean, standard deviation and frequency), we used Mann-Whitney $U$ test for comparison because of the non-normal distribution of the qualitative data. We used Fisher's exact test for analysing the quantitative data. We investigated the correlations between the non-normally distributed data by Spearman's rho correlation analysis. The best cut-off point was calculated with the receiver operating characteristic (ROC) curve analysis. A p value of less than 0.05 was considered statistically significant for this study.

\section{Results}

We enrolled 379 patients in this study. The mean age of patients was $67.44 \pm 7.74$ years; moreover, 135 (35.6\%) patients were younger than 65 years and $244(64.4 \%)$ were equal to or older than 65 years. In total, 99 (26.1\%) patients were taking 5-ARI treatment for at least three months before surgery (Table 1). The minimum, maximum and mean PV measured via transrectal ultrasonography were 30,95 and $53.42 \pm 18.12 \mathrm{~mL}$, respectively. Transfusion (erythrocytes and FFP) was performed in only 9 (2.4\%) of the 379 patients. The age, PV, Plt count, international

Table 1. Demographic data and laboratory findings of the patients who underwent transurethral resection of the prostate with monopolar system

\begin{tabular}{|l|l|l|l|}
\hline \multicolumn{2}{|l|}{} & Min-max & Mean \pm SD \\
\hline Age (year) & & $43-79$ & $67.44 \pm 7.74$ \\
\hline PV $(\mathrm{mL})$ & & $30-95$ & $53.42 \pm 18.12$ \\
\hline $\mathrm{Hb}($ preoperative $)(\mathrm{g} / \mathrm{dL})$ & & $10.1-18$ & $14.21 \pm 1.48$ \\
\hline PIt $\left(10^{3} / \mathrm{mm}^{3}\right)$ & & $101-450$ & $219.95 \pm 59.94$ \\
\hline INR $(0.8-1.2)$ & & $0.73-1.20$ & $1.03 \pm 0.8$ \\
\hline Hb decrease $(\mathrm{g} / \mathrm{dL})$ & & $0.1-6$ & $0.99 \pm 0.87$ \\
\hline & & $\mathbf{n}$ & $\%$ \\
\hline \multirow{2}{*}{$5 \alpha$-reductase inhibitor use } & Yes & 99 & 26.1 \\
\cline { 2 - 4 } & No & 280 & 73.9 \\
\hline \multirow{2}{*}{ Blood product transfusion } & Yes & 9 & 2.4 \\
\cline { 2 - 4 } & No & 370 & 97.6 \\
\hline PV: Prosta & &
\end{tabular}

PV: Prostate volume, $\mathrm{Hb}$ : Haemoglobin, Plt: Platelet, INR: International normalised ratio for prothrombin time, Min: Minimum, Max: Maximum, SD: Standard deviation, $\alpha$ : Alpha 
normalised ratio (INR) for prothrombin activity and the use of 5 -ARI of the patients were not different between the transfusion and non-transfusion groups ( $p>0.05$ ). The preoperative $\mathrm{Hb}$ level of the transfusion group was significantly lower than that of the non-transfusion group $(\mathrm{p}=0.004)$ (Table 2$)$. The mean decrease of preoperative $\mathrm{Hb}$ in the postoperative $48^{\text {th }}$ hour was $0.99 \pm 0.87$ $\mathrm{gr} / \mathrm{dL}$. The preoperative $\mathrm{Hb}$ level was found to be inversely correlated with the postoperative decrease in $\mathrm{Hb}(p=0.000)$. The decrease in $\mathrm{Hb}$ was not associated with age, PV, Plt count, INR and use of 5-ARI ( $p>0.05$ ) (Table 3).

The patients were grouped according to their age: whether they were younger than 65 years or not. The decrease in $\mathrm{Hb}$ was not different between the groups ( $p>0.05)$. The transfusion rates were $3 \%$ and $2 \%$ in the younger and older groups, respectively. There was no statistically significant difference between the groups ( $p>0.05)$. The correlations between decrease in $\mathrm{Hb}$ and other study parameters in both the groups were investigated individually, and the preoperative $\mathrm{Hb}$ level was found to be

\begin{tabular}{|c|c|c|c|}
\hline \multicolumn{4}{|c|}{$\begin{array}{l}\text { Table 2. Observed parameters in the transfusion and non- } \\
\text { transfusion groups }\end{array}$} \\
\hline & \multicolumn{2}{|l|}{ Transfusion } & \multirow{3}{*}{$\mathrm{p}$} \\
\hline & \multicolumn{2}{|l|}{$(-)$} & \\
\hline & Mean \pm SD & Mean \pm SD & \\
\hline Age (Year) & $67.45 \pm 7.66$ & $66.67 \pm 11.17$ & 10.873 \\
\hline $\mathrm{PV}(\mathrm{mL})$ & $53.39 \pm 18.21$ & $54.67 \pm 14.95$ & 10.579 \\
\hline $\mathrm{Hb}$ (preoperative) (g/dL) & $14.26 \pm 1.44$ & $12.32 \pm 2.07$ & ${ }^{1} \mathbf{0 . 0 0 4}{ }^{*}$ \\
\hline PIt $\left(10^{3} / \mathrm{mm}^{3}\right)$ & $219.77 \pm 59.73$ & $227.22 \pm 71.53$ & ${ }^{1} 0.585$ \\
\hline INR $(0.8-1.2)$ & $1.03 \pm 0.08$ & $1.05 \pm 0.05$ & ${ }^{1} 0.425$ \\
\hline $\mathrm{Hb}$ decrease $(\mathrm{g} / \mathrm{dL})$ & $0.95 \pm 0.8$ & $2.89 \pm 1.46$ & $10.000^{*}$ \\
\hline \multicolumn{4}{|c|}{$5 \alpha$-reductase inhibitor use $\mathrm{n}(\%)$} \\
\hline No & $274(\% 74.1)$ & $6(\% 66.7)$ & 20.702 \\
\hline Yes & $96(\% 25.9)$ & $3(\% 33.3)$ & \\
\hline
\end{tabular}

Table 3. Correlations between haemoglobin decrease and observed parameters

\begin{tabular}{|c|c|c|c|c|c|c|}
\hline & \multicolumn{6}{|c|}{$\mathrm{Hb}$ decrease } \\
\hline & \multicolumn{2}{|c|}{$<65$ years } & \multicolumn{2}{|c|}{$\geq 65$ years } & \multicolumn{2}{|l|}{ Total } \\
\hline & $r$ & $p$ & $r$ & $\mathbf{p}$ & $r$ & p \\
\hline \multicolumn{5}{|l|}{ Age (year) } & -0.004 & ${ }^{1} 0.945$ \\
\hline $\mathrm{PV}(\mathrm{mL})$ & -0.032 & ${ }^{1} 0.715$ & 0.077 & 10.231 & 0.034 & 10.508 \\
\hline $\begin{array}{l}\mathrm{Hb} \\
\text { (preoperative) } \\
\text { (g/dL) }\end{array}$ & -0.300 & ${ }^{1} 0.000^{*}$ & -0.147 & ${ }^{1} 0.022^{*}$ & -0.194 & ${ }^{1} 0.000^{*}$ \\
\hline $\begin{array}{l}\text { Plt } \\
\left(10^{3} / \mathrm{mm}^{3}\right)\end{array}$ & -0.088 & ${ }^{1} 0.310$ & -0.089 & ${ }^{1} 0.164$ & -0.087 & ${ }^{1} 0.091$ \\
\hline INR & 0.068 & ${ }^{1} 0.436$ & 0.070 & ${ }^{1} 0.276$ & 0.069 & 10.177 \\
\hline $\begin{array}{l}5 \alpha \text {-reductase } \\
\text { inhibitor use }\end{array}$ & & ${ }^{2} 0.359$ & & ${ }^{2} 0.307$ & & ${ }^{2} 0.791$ \\
\hline
\end{tabular}

'Spearman Rho Correlation analysis, ${ }^{2}$ Mann-Whitney U test, ${ }^{*} \mathrm{p}<0.05$, PV: Prostate Volume, Hb: Haemoglobin, Plt: Platelet, INR: International normalised ratio for prothrombin time inversely correlated with postoperative decrease in $\mathrm{Hb}$ in both younger and older groups ( $\mathrm{p}=0.000$ and $\mathrm{p}=0.022$, respectively) (Table 3).

The area under curve (AUC) was 0.777 , and the standard error was 0.11 in the ROC curve analysis for the preoperative $\mathrm{Hb}$ level, which predicted significant $\mathrm{Hb}$ decrease and need for transfusion after M-TURP. The AUC was significantly higher than 0.5 ( $p=0.015)$. The cut-off value for preoperative $\mathrm{Hb}$ level, which predicted significant $\mathrm{Hb}$ decrease and need for transfusion after M-TURP, was calculated as $12.45 \mathrm{gr} / \mathrm{dL}$ with a sensitivity and specificity of $77.8 \%$ and $86.8 \%$, respectively (Figure 1 ).

\section{Discussion}

Since the 1970s, TURP has been the gold standard for the treatment of BPO after the failure of other medical treatments. TURP is a relatively safe procedure because of advancements in the surgical technique, instrumentation and perioperative management including anaesthesia (6). Postoperative complications such as haematuria or clot retention may prolong the length of hospital stay and increase the estimated medications for treating the complications. Even blood transfusions may be required because of acute haemorrhage.

The incidence rate of transfusion-requiring bleeding after M-TURP was $0.4-7.1 \%$ in the trials conducted before 2010 $(7,8)$. A recent randomised controlled study reported the incidence rate of transfusion-requiring bleeding after M-TURP to be $6.3 \%$ (9). The most common causes of the bleeding after TURP are inadequate bleeding control during the procedure, anticoagulant drug use, comorbidities such as ischaemic heart disease, uncontrolled hypertension in the postoperative period,

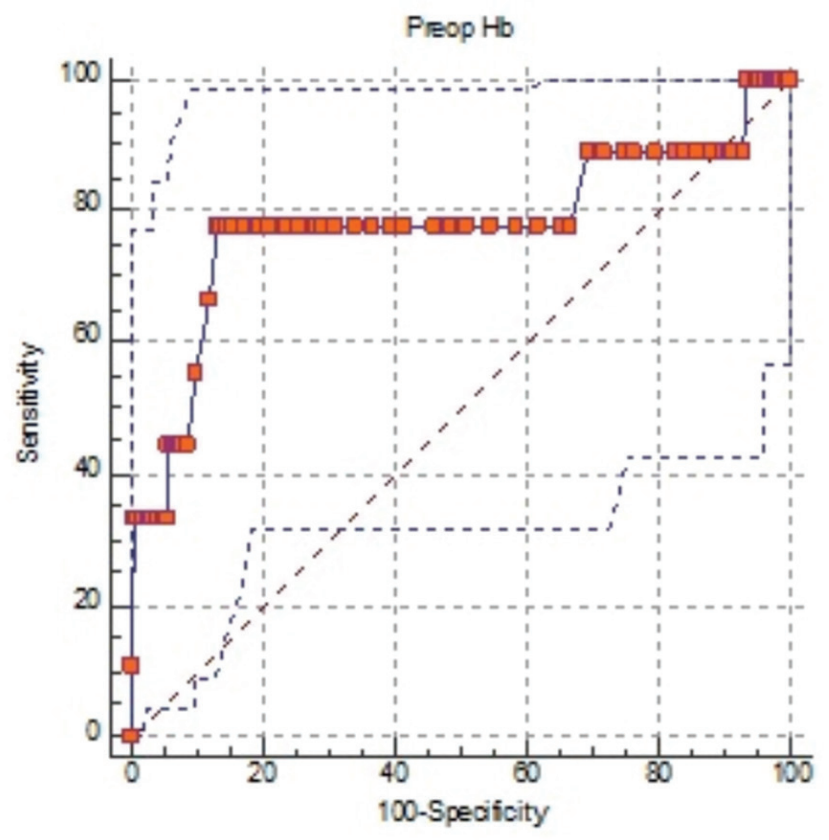

Figure 1. ROC analysis results and AUC for the preoperative $\mathrm{Hb}$ cut-off value predict the substantial decrease in $\mathrm{Hb}$ and transfusion need after M-TURP

ROC: Receiver operating characteristic, AUC: Area under curve, M-TURP: Transurethral resection of the prostate with monopolar system, $\mathrm{Hb}$ : Haemoglobin 
exercises increasing the intra-abdominal pressure, coughing and constipation. In addition to all these factors, the preferred TURP method may be the determinant of bleeding. There are several studies demonstrating that bleeding, clot retention and need for transfusion are more common in M-TURP as compared to bipolar TURP $(10,11,12)$. However, it is reported that these two methods are comparable in terms of bleeding, clot retention and need for transfusion (9). A randomised controlled study reported that the long-term outcomes of M-TURP, photoselective vaporisation of the prostate and need for postoperative transfusion were not different between the two methods (13). The modified M-TURP methods, which reduce bleeding and transfusion rates as compared to the standard M-TURP, are also in use (14).

The mean $\mathrm{Hb}$ decrease with M-TURP was $0.99 \pm 0.87 \mathrm{gr} / \mathrm{dL}$ in our study and in nearly all of the patients; importantly, we did not encounter any clinically important bleeding. The incidence rate of transfusion-requiring bleeding rate $2.4 \%$ with M-TURP in our study, which was consistent with the literature. Among all the parameters, only the preoperative lower $\mathrm{Hb}$ level was found to be associated with clinically important bleeding. The cutoff value of preoperative $\mathrm{Hb}$ level for predicting the substantial decrease of $\mathrm{Hb}$ and the need for transfusion after M-TURP was calculated as $12.45 \mathrm{gr} / \mathrm{dL}$. Of the nine patients who underwent transfusion, seven $(77.8 \%)$ had a preoperative $\mathrm{Hb}$ level lower than this cut-off level.

It is apparent from the literature that the patients undergoing TURP are older than 65 years and are likely to be on multiple medications due to the various co-existing chronic conditions thus more susceptible to postoperative complications (15). These complications may result in more serious conditions due to the delicate physiologies of the older patients (16). In our study, $64.4 \%$ of our patients were equal to or older than 65 years. The patients were grouped according to their age, that is, whether they were younger than 65 years or not. Contrary to the literature, the decrease of $\mathrm{Hb}$ and transfusion rates did not differ between the groups. We believe that this may be due to the study design that included only the index patients after the exclusion of patients who were older than 80 years of age, receiving antithrombotic/anticoagulant drugs, and who had comorbidities.

The preoperative $\mathrm{PV}$, perioperative excessive resection of the prostate and prolonged duration of the operation may increase the risk of bleeding after TURP (17). Reich and colleagues reported that the risk of transfusion-requiring intraoperative/ postoperative bleeding increased with resection weight. Transfusion rates for resection weights greater than 60 grams, $30-60$ grams and less than 30 grams were $9.5 \%, 3.4 \%$ and $2.0 \%$, respectively (18). Some studies showed correlations between the mean resected prostate weight and transfusion rates $(4,19)$. PV in our study ranged widely from 30 to $95 \mathrm{~mL}$ with a mean PV of $53.4 \mathrm{~mL}$. The resected PV was not measured routinely in this study; therefore, it is not shown in the analyses. In our study, preoperative PV measured via transrectal ultrasonography was not found to be associated with a decrease in $\mathrm{Hb}$ in the postoperative $48^{\text {th }}$ hour and transfusion.

Several studies (from 2005 to present) demonstrated that the preoperative use of 5 -ARI reduced perioperative bleeding
$(3,20,21,22)$. However, there were also reports of contrary results $(23,24,25)$. In our study, $99(26.1 \%)$ patients were on 5 -ARI treatment for at least three months before surgery, and a decrease in $\mathrm{Hb}$ in the postoperative $48^{\text {th }}$ hour and transfusion was not associated with the preoperative use of 5-ARI.

There are few studies investigating the need for blood preparation before TURP and the routine control of $\mathrm{Hb}$ level after TURP. Shah and Nethercliffe (26) demonstrated that $\mathrm{Hb}$ decrease in 48 hours after TURP was negligible and except for clinical deterioration, the routine control of $\mathrm{Hb}$ level was unnecessary. Additionally, Hakeem et al. (4) reported that routine biochemical analyses were significantly expensive (\$45), and these analyses should be performed selectively rather than on a routine basis for a standard TURP procedure.

In our clinic, the preoperative blood group analysis, antibody screening and postoperative $\mathrm{Hb}$ level control were performed routinely because of legal concerns in the study period. However, these tests and controls did not yield the expected benefits in the management of the patients, and nearly all of the patients were discharged without necessity of transfusion. These tests, which are performed because of legal concerns and are under debate in terms of medical indications, appeared to cause a great waste of resources in four years.

As a clinical consequence, patients should not routinely be tested for blood group or antibody screening before M-TURP, except for the following clinical conditions: Hb level lower than $12.4 \mathrm{~g} / \mathrm{dL}$ preoperatively, the absence of an active transfusion unit of the centre where the operation is performed, or rare blood group of the patient.

\section{Study Limitations}

The retrospective design of this study and the heterogeneity between groups are some limitations of this study. Additionally, a separate statistical evaluation could not be made for this group of patients because the number of cases for M-TURP with PV over $80 \mathrm{~mL}$ was not sufficient to obtain a good-quality statistical data.

\section{Conclusion}

M-TURP is still a safe and efficient method for bleeding control in BPO treatment in developing countries despite some potential risks. Additionally, routine tests for blood group or antibody screening do not alter the clinical management. The authors recommend selective blood testing based on the clinical need of patients.

\section{Acknowledgements}

Publication: This study was presented in the $6^{\text {th }}$ Congress of Minimally Invasive Surgery 5-8 March 2020, Antalya.

Contribution: There is not any contributors who may not be listed as authors.

Conflict of Interest: No conflict of interest was declared by the authors.

Financial Disclosure: The authors declared that this study received no financial support. 


\section{Ethics}

Ethics Committee Approval: Due to the fact that this study is a retrospective, ethical committee approval was not obtained.

Informed Consent: Retrospective study.

Peer-review: Internally peer-reviewed.

\section{Authorship Contributions}

Supervision: Ö.Y., H.H.T., Critical Review: Ö.Y., Concept: S.A., Design: S.A., C.E., Data Collection or Processing: E.Ö., M.P., Analysis or Interpretation: C.E., K.K., Literature Search: H.H.T., Writing: S.A., C.E.

\section{References}

1. Gravas TB S, Drake M, Gacci $M$, et al. Guidelines Associates: M. Karavitakis SM, V. Sakkalis, R. Umbach. EAU Guidelines 2016;2016:15-23.

2. Reich $O$, Gratzke C, Stief CG. Techniques and long-term results of surgical procedures for BPH. Eur Urol 2006;49:970-978.

3. Bansal A, Arora A. Transurethral Resection of Prostate and Bleeding: A Prospective, Randomized, Double-Blind Placebo-Controlled Trial to See the Efficacy of Short-Term Use of Finasteride and Dutasteride on Operative Blood Loss and Prostatic Microvessel Density. J Endourol 2017;31:910-917.

4. Hakeem AR, Sairam K, Plail R. The Value of Blood Tests Following Transurethral Resection of the Prostate. UroToday International Journal 2009;2.

5. Franchini M, Marano G, Mengoli $C$, et al. Red blood cell transfusion policy: a critical literature review. Blood Transfus 2017;15:307-317.

6. Issa MM. Technological advances in transurethral resection of the prostate: bipolar versus monopolar TURP. J Endourol 2008;22:1587-1595.

7. Rassweiler J, Teber D, Kuntz R, Hofmann R. Complications of transurethral resection of the prostate (TURP) incidence, management, and prevention. Eur Urol 2006;50:969-979.

8. Wendt-Nordahl G, Bucher B, Hacker A, et al. Improvement in mortality and morbidity in transurethral resection of the prostate over 17 years in a single center. J Endourol 2007;21:1081.

9. Skolarikos A, Rassweiler J, de la Rosette JJ, et al. Safety and Efficacy of Bipolar Versus Monopolar Transurethral Resection of the Prostate in Patients with Large Prostates or Severe Lower Urinary Tract Symptoms: Post Hoc Analysis of a European Multicenter Randomized Controlled Trial. J Urol 2016;195:677-684.

10. Bhansali M, Patankar S, Dobhada S, Khaladkar S. Management of large (>60 g) prostate gland: PlasmaKinetic Superpulse (bipolar) versus conventional (monopolar) transurethral resection of the prostate. J Endourol 2009;23:141-146.
11. Isıkay L, Bozlu M. Monopolar TURP sona mı eriyor? BPH'da cerrahi tedavide son durum. Bulletin of Urooncology 2009;4:34-37.

12. Mamoulakis C, Ubbink DT, de la Rosette JJ. Bipolar versus monopolar transurethral resection of the prostate: a systematic review and metaanalysis of randomized controlled trials. Eur Urol 2009;56:798-809.

13. Bouchier-Hayes DM. Photoselective vaporization of the prostate: towards a new standard. Prostate Cancer Prostatic Dis 2007;10:10-14.

14. Sjöström C, Bergkvist $M$, Thulin $H$, et al. Reduced bleeding with DRY CUT $®$ transurethral resection of the prostate (TURP) compared to standard TURP. Scand J Urol 2019;53:235-239.

15. Piccini JP, Hammill BG, Sinner MF, et al. Incidence and prevalence ofatrial fibrillation and associated mortality among Medicare beneficiaries. 1993-2007, Circ Cardiovasc Qual Outcomes 2012;5:85-93.

16. Saxton A, Velanovich V. Preoperative frailty and qualityof life as predictors of postoperative complications. Ann Surg 253:1223-1229.

17. El Malik EM, Ibrahim Al, Gahli AM, et al. Risk factors in prostatectomy bleeding: preoperative urinary infection is the only reversible factor. Eur Urol 2000;37:199-204.

18. Reich O, Gratzke C, Bachmann A, et al: Morbidity, mortality and early outcome of transurethral resection of the prostate: a prospective multicenter evaluation of 10.654 patients. J Urol 2008;180:246-249.

19. Borboroglu P, Kane C, Ward J, et al. Immediate and late post-operative complications of transurethral resection of the prostate in the 1990s. J Urol 1999;162:1307-1310.

20. Crea G, Sanfilippo G, Anastasi G, et al. Pre-surgical finasteride therapy in patients treated endoscopically for benign prostatic hyperplasia. Urol Int 2005;74:51-53.

21. Kim KS, Jeong WS, Park SY, et al. The effect of two weeks of treatment with dutasteride on bleeding after transurethral resection of the prostate. World J Mens Health 2015;33:14-19.

22. Pastore AL, Mariani $S$, Barrese $F$, et al. Transurethral resection of prostate and the role of pharmacological treatment with dutasteride in decreasing surgical blood loss. J Endourol 2013;27:68-70.

23. Lund L, Moller Ernst-Jensen K, Torring N, Nielsen JE. Impact of finasteride treatment on perioperative bleeding before transurethral resection of the prostate: A prospective randomized study. Scand J Urol Nephrol 2005;39:160-162.

24. Arratia-Maqueo JA, Garza-Corte's R, Go'mez-Guerra LS, CortésGonzález JR. Effect of one month treatment with dutasteride on transurethral resection of the prostate. Actas Urol Esp 2010;34:866-869.

25. Tuncel A, Ener K, Han O, et al. Effects of short-term dutasteride and Serenoa repens on perioperative bleeding and microvessel density in patients undergoing transurethral resection of the prostate. Scand I Urol Nephrol 2009;43:377-382.

26. Shah J, Nethercliffe J. Is routine post-operative haemoglobin measurement required after transurethral resection of prostate? Transfus Med 2004;14:343-346. 